\title{
Epidemiologic Evaluation and Clinical Aspects of Superficial Corneal Foreign Body Injuries at a Tertiary Referral Center in İstanbul
}

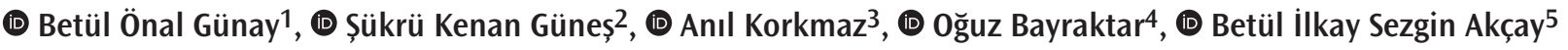 \\ ${ }^{1}$ Clinic of Ophthalmology, Trabzon Kanuni Training and Research Hospital, Trabzon, Turkey \\ ${ }^{2}$ Clinic of Ophthalmology, Sușehri State Hospital, Sivas, Turkey \\ ${ }^{3}$ Clinic of Ophthalmology, İzmir Bozyaka Training and Research Hospital, İzmir, Turkey \\ ${ }^{4}$ Department of Ophthalmology, İstanbul University İstanbul Faculty of Medicine, İstanbul, Turkey \\ ${ }^{5}$ Clinic of Ophthalmology, Ümraniye Training and Research Hospital, İstanbul, Turkey
}

\begin{abstract}
Aim: To assess the demographic characteristics and clinical aspects of superficial corneal foreign body (CFB) trauma, as well as to estimate the impact of awareness of CFB scar on wearing protective goggles (PG).

Materials and Methods: A total of 238 patients were enrolled in this prospective study. Four groups were designated, namely group 1-metal industry workers, group 2-construction workers, group 3-workers with different occupations who had considerable risk for CFB trauma and group 4-miscellaneous patients with low risk for CFB trauma.

Results: There were 234 (98.3\%) men and four (1.7\%) women in the study. The mean age was 33.96 \pm 10.54 years (range, 3-69 years). There were 126 patients (52.9\%) in group 1, 53 patients (22.3\%) in group 2, 27 patients (11.3\%) in group 3 and 32 patients (13.4\%) in group 4. Seventy-nine patients (38.4\%) did not use PG, while, 67 patients (32.5\%) occasionally used PG, 34 patients (16.5\%) frequently used PG and 26 patients (12.6\%) routinely used PG. Awareness of CFB scar was significantly lower in patients who did not use PG $(p<0.05)$.

Conclusion: The awareness of CFB scar was significantly lower among patients who never used PG. This could be avoided by arranging training programs for workers.
\end{abstract}

Keywords: Corneal foreign body, epidemiology, protective goggle use, trauma

\section{Introduction}

Corneal foreign body (CFB) trauma is a common eye injury in the emergency departments (ED) (1). The CFB trauma is mostly associated with occupational accidents frequently seen in construction and metal industry workers (2). Metal CFBs carry the risk of corneal scarring with decreased visual quality if the injury lies within the visual axis or the risk of a secondary infection (3). Furthermore, CFB trauma also causes an economic burden. A study in Turkey stated that unregistered employment is relatively higher and this forces workers to remove CFBs by themselves (4).
Several studies have been reported on demographic and clinical characteristics of CFB trauma. Using protective goggles (PG) has been suggested to prevent workers from CFB trauma (5).

In the present study, we aimed to evaluate the demographic and clinical characteristics of the patients who suffered from CFB trauma and who were treated in the ED. We also aimed to estimate the impact of awareness of CFB scar on wearing PG.

\section{Materials and Methods}

This study was conducted in patients presenting to the ED with CFB between July 2015 and November 2015. The mean 
number of daily ED admissions and emergency eye department admissions were means 1300 and 30, respectively. Patients with an eye emergency who were consulted from ED were examined in Ophthalmology Department at the same hospital. Only patients with CFB were included in the study. Patients who had eye emergency other than CFB trauma, including open globe injuries such as penetrating and/or perforating ocular trauma with or without a intraocular foreign body, blunt ocular trauma, eyelid trauma, chemical ocular trauma and orbital fractures were excluded from the study. All patients signed written informed consent before taking part in the study and a local ethical approval was obtained. The study followed the principles outlined in the Declaration of Helsinki.

Patients with CFB trauma were subjected to a routine ophthalmic examination. All examinations were performed by an ophthalmologist. The location of the CFB on the cornea was noted considering the quadrants (central, superonasal, superotemporal, inferonasal or inferotemporal). The size of the CFB was measured with its largest diameter under slit-lamp biomicroscopic examination. The number of hours from injury to presentation was recorded. A questionnaire was also filled out for all patients regarding age, gender, occupation, type of CFB, number of previous CFB removal, PG use and awareness of CFB scar.

Management of CFB was performed in a standard manner. After applying topical anesthetic drop (proparacaine hydrochloride $0.5 \%)$, CFB was removed with a 26-gauge needle under slit-lamp. Topical antibiotic treatment (lomefloxacin) was ordered four times daily for four days after the procedure. Eye patching was not suggested in any of the patients (6). Patients were controlled two days after treatment.

Four groups were designated in the study, namely group 1-metal industry workers, group 2-construction workers, group 3-workers in different occupations who had considerable risk for CFB trauma (sweeper, technician, junk dealer and electrician) and group 4-miscellaneous patients with low risk for CFB trauma (student, engineer, housewife and children).

\section{Statistical Analysis}

Statistical Package for the Social Sciences (SPSS 22.0) program was used for the statistical analysis. Descriptive statistical methods were expressed as mean and standard deviation. Anova and Kruskal-Wallis tests were used to compare quantitative data according to distribution. Pearson and Spearman's rho correlation methods were performed to assess the relationship between the parameters according to the distribution. Chisquare test was used for comparison of the rates. $p<0.05$ was considered statistically significant.

\section{Results}

A total of 238 patients were included in the study. There were four women (1.7\%) and 234 men (98.3\%) in the study. The mean age of the study population was 33.96 \pm 10.54 years (range, 3-69 years). There were 126 patients (52.9\%) in group 1, 53 patients $(22.3 \%)$ in group 2, 27 patients (11.3\%) in group 3 and 32 patients (13.4\%) in group 4. No significant difference was found between the groups in terms of age $(p=0.719)$. The CFB was found in the right eye in 112 patients (47.1\%) and in the left eye in 126 patients (52.9\%). The type of the CFBs in each group is summarized in Table 1.

The CFB was located in the central cornea in 77 patients (32.4\%), in the inferotemporal quadrant in 68 patients (28.6\%), in the inferonasal quadrant in 44 patients (18.5\%), in the superotemporal quadrant in 30 patients (12.6\%) and in the superonasal quadrant in 19 patients (8\%). No significant difference was observed between the groups in terms of CFB location ( $p>0.05$ ) (Table 2).

The mean CFB size was $0.30 \pm 0.22 \mathrm{~mm}$ (range, 0.02-1.20 mm) in the study. The mean time from the CFB injury to presentation was 28.44 \pm 32.77 hours (range, 0.3-240 hours). The time from the CFB injury to presentation was significantly associated with the number of previous CFB removals. Increasing number of CFB removals was associated with decreased time from CFB trauma to presentation $(r=0.150 ; p=0.021)$.

Regarding the use of $P G$ among patients with a risk of CFB trauma, 79 patients (38.4\%) never used PG. Sixty-seven patients (32.5\%) occasionally used PG, 34 patients (16.5\%) frequently used PG and 26 patients (12.6\%) routinely used PG.

Table 1. The types of corneal foreign bodies

\begin{tabular}{llllll}
\hline & Group 1 & Group 2 & Group 3 & Group 4 & p \\
\hline Metal & $121(96 \%)$ & $40(75.5 \%)$ & $25(92.6 \%)$ & $24(75 \%)$ & $7(21.9 \%)$ \\
Stone & $5(4 \%)$ & $13(24.5 \%)$ & $2(7.4 \%)$ & $1(3.1 \%)$ & $0.001^{\text {a }}$ \\
Wood & $0(0 \%)$ & $0(0 \%)$ & $0(0 \%)$ & \\
\hline
\end{tabular}

Group 1: Metal industry workers, Group 2: Construction workers; Group 3: Workers with different occupations who had considerable risk for corneal foreign body trauma, Group 4: Patients with low risk for corneal foreign body trauma

${ }^{a}$ Chi-square $p<0.01$ 
that higher number of previous CFB removals was related to decreased time from CFB trauma to presentation to hospital. A shorter interval of hospital admission can be a protective factor for the patient from possible future harmful effect of a CFB, such as corneal ulcer or corneal scar.

It has been stated that the use of PG can protect most of the workers from CFB trauma, as well as from possible scarring in the cornea (1). It has also been shown that leaving the CFB for more than 24 hours causes the rust ring to result in a corneal scar eventually (7). We observed that only $12.6 \%$ of patients at risk of CFB trauma always wore PG during working. Vast majority of such patients (91\%) who did not wear PG during working were not aware of the possible scar of the CFB. These findings may indicate that majority of the subjects do not have enough knowledge of whether they are at risk of CFB scar whether or not while working. Actually, this represents an important issue for occupational health. An experienced on-site physician should inform the workers about such occupational accident, irrespective of their social and educational status. Also, the employer should be informed in order to take preventive measures for CFB injury.

Several methods have been used in an attempt to remove the rust ring of the CFB, including an electric burr or a hypodermic needle $(8,9)$. The electrical burr has been demonstrated to be associated with deeper stromal damage after CFB removal (9). In our study, we successfully used a 26-gauge hypodermic needle in order to remove the CFB and its rust.

Studies did not suggest a routine eye patch for corneal abrasions, because it does not have any effect on healing time and pain (10). It has also been indicated that smaller abrasions, as in CFB trauma, could be treated only with antibiotic ointments (11). Following CFB removal, all patients in the current study were prescribed ocular antibiotic drops without eye patching, and then patients were re-assessed two days after the procedure. We found that such treatment approach seems to be a safe and practical method for CFB injuries in terms of avoiding secondary infection and providing patient rehabilitation.

\section{Study Limitations}

The inclusion of relatively small number of patients can be one of the drawbacks of the study.

\section{Conclusion}

Corneal foreign body trauma is a preventable healthcare problem. Our study demonstrated that patients were relatively unaware of the further complications related to CFB. Such injuries and related complications can be better avoided by taking preventive measures at workplaces and by informing individuals on this issue.

\section{Ethics}

Ethics Committee Approval: Ümraniye Training and Research Hospital, approval number: B.10.1.TKH.4.34.H.GP.0.01/41.

Informed Consent: N/A.

Peer-review: Externally peer-reviewed.

\section{Authorship Contributions}

Surgical and Medical Practices: B.Ö.G., S.K.G., A.K., O.B., Concept: B.Ö.G., S..K.G., A.K., O.B., B.I.S.A., Design: B.Ö.G., S.K.G., A.K., O.B., B.I.S.A., Data Collection or Processing: B.Ö.G., S.K.G., A.K., O.B., B.I.S.A., Analysis or Interpretation: B.Ö.G., B.I.S.A., Literature Search: B.Ö.G., S..K.G., A.K., O.B., B.I.S.A., Writing: B.Ö.G., Ş.K.G., A.K., O.B., B.I.S.A.

Conflict of Interest: No conflict of interest was declared by the authors.

Financial Disclosure: The authors declared that this study received no financial support.

\section{References}

1. Zimmerman DR, Shneor E, Millodot M, Gordon-Shaag A. Corneal and conjunctival injury seen in urgent care centres in Israel. Ophthalmic Physiol Opt. 2019;39:46-52.

2. Ramakrishnan T, Constantinou M, Jhanji V, Vajpayee RB. Corneal metallic foreign body injuries due to suboptimal ocular protection. Arch Environ Occup Health. 2012;67:48-50.

3. Sayegh JS, Lahham S, Woodhouse L, Seong J, McCoy CE. Creation of a Realistic Model for Removal of a Metallic Corneal Foreign Body for Less than $\$ 75$. West J Emerg Med 2017;18:121-5.

4. Ozkurt ZG, Yuksel H, Saka G, Guclu H, Evsen S, Balsak S. Metallic corneal foreign bodies: an occupational health hazard. Arq Bras Oftalmol. 2014;77:81-3.

5. Ahmed F, House RJ, Feldman BH. Corneal Abrasions and Corneal Foreign Bodies. Prim Care. 2015;42:363-75.

6. Lim CH, Turner A, Lim BX. Patching for corneal abrasion. Cochrane Database Syst Rev. 2016;7:CD004764.

7. Brock G, Gurekas V. The occasional corneal rust ring removal. Can J Rural Med. 2013;18:140-2.

8. Fraenkel A, Lee LR, Lee GA. Managing corneal foreign bodies in office-based general practice. Aust Fam Physician. 2017;46:89-93.

9. Brown N, Clemett R, Grey R. Corneal rust removal by electric drill. Clinical trial by comparison with manual removal. Br J Ophthalmol. 1975;59:586-9.

10. Menghini M, Knecht PB, Kaufmann C, Kovacs R, Watson SL, Landau K, et al. Treatment of traumatic corneal abrasions: a three-arm, prospective, randomized study. Ophthalmic Res. 2013;50:13-8.

11. Segal KL, Fleischut PM, Kim C, Levine B, Faggiani SL, Banerjee S, et al. Evaluation and treatment of perioperative corneal abrasions. J Ophthalmol. 2014;2014:901901. 